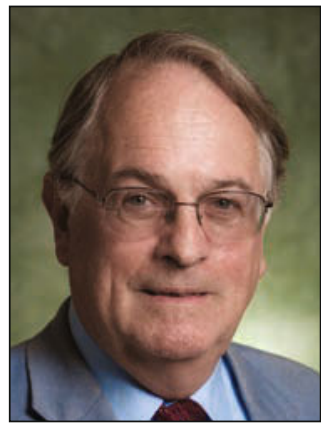

\section{Stan Whittingham selected for 2018 David Turnbull Lectureship Award}

$\mathrm{T}$ he Materials Research Society's (MRS) David Turnbull Lectureship Award recognizes the career of a scientist who has made outstanding contributions to understanding materials phenomena and properties through research, writing, and lecturing, as exemplified by the late David Turnbull of Harvard University. M. Stanley Whittingham, Binghamton University, The State University of New York, has been selected to give the Turnbull Lecture at the 2018 MRS Fall Meeting in Boston. He is cited "for fundamental contributions to solid-state ionics, including the discovery of the key role of intercalation mechanisms, and the development and commercialization of rechargeable $\mathrm{Li}$-ion batteries."

Whittingham received his bachelor's and $\mathrm{PhD}$ degrees in chemistry from the University of Oxford, where he established his initial expertise in solid-state inorganic chemistry through his early work on tungsten bronzes. For more than 45 years, he has laid the groundwork for lithium rechargeable battery development, starting with the basic idea of utilizing intercalation compounds as electrode materials and demonstrating the viability of these technologies for commercial manufacturing.
Whittingham first moved to the United States to work with Professor Bob Huggins at Stanford University. His work in solid-state ionics and beta alumina led to his appointment as the director at ExxonMobil. He later joined the faculty at Binghamton University as professor and the founding director of the Institute for Materials Research.

Perhaps the most significant development in solid-state ionics and battery materials has been the discovery and commercialization of a large class of intercalation compounds as electrode materials. Whittingham ushered in this revolution with his early insights into the potential for ion insertion in layered compounds and the development and commercialization of $\mathrm{Li}$-ion batteries using $\mathrm{LiAl}$ alloy anodes and $\mathrm{TiS}_{2}$ cathodes.

$\mathrm{He}$ has received the Distinguished Research Award from the American Chemical Society, the Lifetime Achievement Technology Award from NAAT Batt International, and the IBA Yeager Award. He also serves on the MRS Bulletin Editorial and Energy Quarterly Boards.

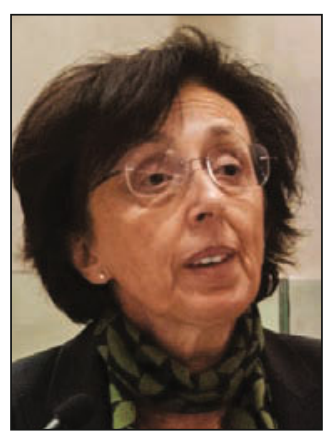

\section{Giulia Galli receives 2018 Materials Theory Award}

$\mathrm{T}$ The Materials Research Society (MRS) has named Giulia Galli, The University of Chicago, as the recipient of the 2018 Materials Theory Award "for the development of advanced firstprinciples simulation methods and their application to the understanding, prediction and design of complex nanostructured materials." Galli will be recognized at the 2018 MRS Fall Meeting in Boston. The Materials Theory Award, endowed by Toh-Ming Lu and GwoChing Wang, "recognizes exceptional advances made by materials theory to the fundamental understanding of the structure and behavior of materials."

Galli is the Liew Family Professor of Molecular Engineering and professor of chemistry at The University of Chicago and senior scientist at Argonne National Laboratory. She is recognized for her contributions to the fields of computational condensed matter, materials science, and nanoscience, most notably, first-principles simulations of materials and liquids.

Over the years, Galli has developed a number of novel theoretical and computational methods that have greatly extended the scope of ab initio molecular dynamics. She also has developed linear scaling algorithms for electronic-structure calculations and methods based on many body perturbation theory to study spectroscopic properties of materials. These methods are now implemented in several codes. Galli made many predictions of the properties of liquids, solids, and nanostructures that have been confirmed by experiments.

Galli received her $\mathrm{PhD}$ degree in physics from the International School for Advanced Studies, Trieste, Italy. She held postdoctoral fellowships at the University of Illinois at Urbana-Champaign and the IBM Research Division in Zurich, Switzerland. She is a Fellow of the American Physical Society and the American Association for the Advancement of Science, the recipient of the Lawrence Livermore National Laboratory Science and Technology Award, the US Department of Energy Award of Excellence, and the American Physical Society 2019 David Adler Lectureship Award in Materials Physics. 